\title{
The Microwave-assisted Synthesis of Polyethersulfone (PES) as A Matrix in Immobilization of Candida antarctica Lipase B (Cal-B)
}

\author{
Khusna Widhyahrini ${ }^{1}$, Nurrahmi Handayani², Deana Wahyuningrum ${ }^{3, *}$, Santi Nurbaiti ${ }^{4}$, \\ Cynthia Linaya Radiman ${ }^{5}$ \\ ${ }^{1}$ Master and Doctor Study Program, Department of Chemistry, Institut Teknologi Bandung, Indonesia \\ ${ }^{2}$ Analytical Chemistry Research Division, Department of Chemistry, Institut Teknologi Bandung, Indonesia \\ ${ }^{3}$ Organic Chemistry Research Division, Department of Chemistry, Institut Teknologi Bandung, Indonesia \\ ${ }^{4}$ Biochemistry Research Division, Department of Chemistry, Institut Teknologi Bandung, Indonesia \\ ${ }^{5}$ Physical Chemistry Research Division, Department of Chemistry, Institut Teknologi Bandung, Indonesia
}

Received: 15th November 2016; Revised: $23^{\text {rd }}$ May 2017; Accepted: 24th May 2017; Available online: 27th October 2017; Published regularly: December 2017

\begin{abstract}
Candida antarctica lipase B (Cal-B) has been widely used in the hydrolysis reaction. However, it has some weaknesses, such as: forming of the heavy emulsion during the process, which is difficult to resolve and has no reusability. Therefore, it needs to be immobilized into a suitable matrix. One of the suitable supporting materials is polyethersulfone (PES) and its synthesis becames the objective of this paper. The PES was synthesized via a polycondensation reaction between hydroquinone and 4,4'dichlorodiphenylsulfonein $N$-methylpyrrolidone (NMP) as solvent using Microwave Assisted Organic Synthesis (MAOS) method at $170{ }^{\circ} \mathrm{C}$ for 66 minutes using an irradiation power of 300 watt. The synthesized PES was characterized by FTIR and ${ }^{1} \mathrm{H}-\mathrm{NMR}(500 \mathrm{MHz}, \mathrm{DMSO}-d 6)$. Then the PES membrane was prepared from $20 \%$ of the optimized mixtures of PES, PSf (polysulfone), and PEG (polyethylene glycol) dissolved in $80 \%$ NMP. The Cal-B was immobilized on the PES membrane by mixing it in a shaker at $30^{\circ} \mathrm{C}$ and $100 \mathrm{rpm}$ for $24 \mathrm{~h}$ using phosphate buffered saline (PBS). The identification of the immobilized Cal-B was done by using FTIR-ATR spectroscopy and SEM micrographs. The results of Lowry assay showed that the 'Cal-B immobilized' blended-membrane has a loading capacity of 91 $\mathrm{mg} / \mathrm{cm}^{2}$ in a membrane surface area of $17.34 \mathrm{~cm}^{2}$. In this work, the activity of immobilized Cal-B was twice higher than the native enzyme in $p$-NP ( $p$-Nitrophenolpalmitate) hydrolyzing. The results indicated that the synthesized PES showed a good performance when used as a matrix in the immobilization of Cal-B. Copyright (C) 2017 BCREC Group. All rights reserved
\end{abstract}

Keywords: Polyethersulfone (PES); Microwave Assisted Organic Synthesis (MAOS); Immobilization; Lipase; Candida antarctica lipase B (Cal-B)

How to Cite: Widhyahrini, K., Handayani, N., Wahyuningrum, D., Nurbaiti, S., Radiman, C.L. (2017). The Microwave-assisted Synthesis of Polyethersulfone (PES) as A Matrix in Immobilization of Candida antarctica Lipase B (Cal-B). Bulletin of Chemical Reaction Engineering \& Catalysis, 12 (3): 343-350 (doi:10.9767/bcrec.12.3.774.343-350)

Permalink/DOI: http://dx.doi.org/10.9767/bcrec.12.3.774.343-350

* Corresponding Author.

E-mail: deana@chem.itb.ac.id (Wahyuningrum, D.) 


\section{Introduction}

Candida antarctica Lipase B (Cal-B) has a superiority in industrial scale. It was used as a biocatalyst and shows a high degree of selectivity during the esterification and transesterification reactions as in the hydrolysis of triglyceride to form fatty acids and glycerol [1-2]. However, the weakness of lipase catalysis is the forming of heavy emulsion during the process which is difficult to resolve and has no reusability [3]. Therefore, the immobilization technique can be used to improve lipase utilization and reusability by maintaining its catalytic effectiveness. In addition, the materials to be used as matrix for the lipase immobilization should have good mechanical characteristics. Polymeric membrane is one of the materials used as matrix for immobilized system [4]. Polyethersulfone (PES) is one of the synthetic polymers which can be used as ultrafiltration membrane and other functional membranes [5]. PES have several good characteristics such as high resistance to heat and chemicals, and have good mechanical strength [6]. So, the PES has been used as a matrix in many immobilization systems for Candida rugosa, Comamonas testostroni, Bovine Serum Albumin (BSA), heparin, and $\mathrm{TiO}_{2}$ [11-15]. Furthermore, the synthesized PES derivative was used as one of the components in the matrix used for the CalB immobilization and showed good results in Cal-B catalysis activity and has better performance compared to previous studies [21-25].

Many methods have been developed to synthesize PES. Some studies reported that the PES was synthesized by using conventional method, i.e. refluxing the reaction mixtures for three hours in various conditions $[7,11,16]$. Since the optimum condition in the synthesis of PES is crucial to obtain better yields of product in shorter reaction time, the modification of experimental condition for synthesizing PES became the main objective of this research. The synthesized PES was then used as a matrix for Cal-B immobilization.

\section{Material and Methods}

\subsection{Materials}

All solvents and materials were used without further purification, i.e. 4, $4^{\prime}$ dichlorodiphenylsulfone (DCDPS) (Chemical Industries, Co, Ltd; 98\%), Cal-B in dried form (Sigma Aldrich), hydroquinone (Sigma Aldrich, 99\%), BSA (Bovine serum albumin) (Merck, 98\%), $\mathrm{K}_{2} \mathrm{CO}_{3}$ (Merck, 99.9\%), $\mathrm{Na}_{2} \mathrm{CO}_{3}$ (Merck, $99.9 \%$ ), $\mathrm{K}_{2} \mathrm{HPO}_{4}$ (Merck, 99\%), $\mathrm{CuSO}_{4} .2 \mathrm{H}_{2} \mathrm{O}$,
(Merck, 99\%), sodium-potassium tartrate (Merck, 99\%), $\mathrm{KH}_{2} \mathrm{PO}_{4}$ (Merck, 99.5\%), methanol (Merck, 95\%), acetone (Merck, 95\%), toluene (Merck, 99.9\%), polysulfone/PSf (Merck, $825 \mathrm{Da}$ ), polyethylene glycol/PEG 400 (Merck, $400 \mathrm{Da}$ ), p-NPP (Sigma Aldrich, 99\%), FolinCiocalteu reagent, $N$-methylpyrollidone / NMP (Merck, 99.5\%), $p$-nitrophenolpalmitate ( $p$ NPP), DMSO (dimethyl sulfoxide)- $d 6$, nitrogen gas (Aneka Gas, 75\%), and demineralized water (aqua dm).

\subsection{Methods}

\subsubsection{Synthesis of PES}

In this procedure, $2.78 \mathrm{~g}$ of DCDPS and 4.14 $\mathrm{g}$ of $\mathrm{K}_{2} \mathrm{CO}_{3}$ were placed in a three-necked flask and mixed with $30 \mathrm{~mL}$ of toluene and $20 \mathrm{~mL}$ of NMP. The flask equipped with a condenser was placed in a MAS-II Sineo ${ }^{\circledR}$ microwave oven reactor, and then subsequently a Dean-Stark trap apparatus was attached to the condenser. Afterwards, the hydroquinone was added gradually into the reaction mixtures and the reaction was carried out in the microwave cavity using an irradiation power of 300 Watt at $170{ }^{\circ} \mathrm{C}$ for 66 minutes with continuous nitrogen gas purging. After the completion of reaction, the hot green thick solution was directly precipitated in a mixture of water and methanol (1:1 in volume). The precipitated product was washed in hot water, then in methanol and ethanol. Finally, it was dried at $70{ }^{\circ} \mathrm{C}$ under vacuum condition.

\subsubsection{Preparation of blended-PES membrane}

A mixture of PES and polysulfone with a total polymer concentration of $18 \%$ was blend with a $2 \%$ of PEG and dissolved in $80 \%$ of NMP. The blending process was carried out in a glass vial by stirring at room temperature for 4 days. The casting solution was poured onto a $10 \times 20 \mathrm{~cm}$ glass plate and casted to form a thin layer approximately $2 \mathrm{~mm}$ in thickness. After that, the glass plate was immersed into a demineralized water bath at room temperature to form a thin layer membrane. The membrane was further dried at room temperature for 24 hours.

\subsubsection{Candida antarctica Lipase B immobiliza-} tion

The Cal-B solution was prepared by dissolving $50 \mathrm{mg}$ Cal-B in a $1 \mathrm{mg} / \mathrm{mL}$ phosphate buffer solution (PBS) at $\mathrm{pH}$ 7.0. The membrane with a surface area of $4.7 \mathrm{~cm}^{2}$ was placed in a $50 \mathrm{~mL}$ beaker glass, and the $5 \mathrm{~mL}$ Cal-B solu- 
tion was added at $30{ }^{\circ} \mathrm{C}$ and agitated at 100 $\mathrm{rpm}$ for $24 \mathrm{~h}$. The membrane was removed from the solution, subsequently washed with demineralized water. The solution and washing solution was kept in the beaker glass for enzyme loading determination. The membrane was dried at room temperature for approximately 3 hours to be further analyzed (FTIR-ATR and SEM).

\subsubsection{Enzyme loading determination}

Determination of enzyme loading was done by Lowry assay protocol [17]. A complex reagent consisted of 3 components was prepared prior to analysis. The A Lowry component was a solution with a concentration of $2 \%(\mathrm{w} / \mathrm{v})$ $\mathrm{Na}_{2} \mathrm{CO}_{3}$ and $0.6 \%(\mathrm{w} / \mathrm{v}) \mathrm{NaOH}$, while the B solution was $2 \%(\mathrm{w} / \mathrm{v}) \mathrm{CuSO}_{4} .2 \mathrm{H}_{2} \mathrm{O}$ in demineralized water and the $\mathrm{C}$ solution was $2 \%(\mathrm{w} / \mathrm{v})$ sodium-potassium tartrate in demineralized water. Then the three components were mixed in a volume ratio of 100:1:1. The BSA standard solutions were prepared with a variation of 0,2 , $4,6,8$, and $10 \mathrm{mg} / \mathrm{L}$. One $\mathrm{mL}$ of standard, or sample solution or washing solution was added to $1 \mathrm{~mL}$ of $2 \mathrm{~N} \mathrm{NaOH}$ solution, and subsequently hydrolyzed at $100{ }^{\circ} \mathrm{C}$. The hydrolyzed samples or standard solutions were allowed to cool to room temperature, and then added by 5 $\mathrm{mL}$ of complexing reagent. Folin ciocalteu reagent was added to each solution after settling for 10 minutes, and then subsequently placed in the dark room for 60 minutes. Afterwards, the absorbance of each solution was measured at the $l_{\max }(660 \mathrm{~nm})$ using UV-vis spectrophotometer.

The amount of enzyme loading was calculated as:

$$
M_{i l}=\frac{\left(M_{l s}-M_{u l}\right)}{L_{m}}
$$

where, $M_{i l}$ is the amount of immobilized lipase on PES membrane surface $(\mathrm{mg}), M_{l s}$ is the lipase stock mass $(\mathrm{mg}), M_{u l}$ is the lipase mass (mg), and $L_{m}$ is the membrane surface area $\left(\mathrm{cm}^{2}\right)$. The mass of lipase stock and lipase were calculated from the absorbance of protein by Lambert-Beer equation.

\subsubsection{Lipase activity determination}

Immobilized lipase activity was determined based on Cal-B and immobilized Cal-B ability to catalyze the hydrolysis reaction of $p$-NPP as the substrate. The stock of substrate solutions were prepared by mixing $47.5 \mathrm{~mL}$ PBS (1 M, $\mathrm{pH} 7$ ), $2.0 \mathrm{~mL}$ ethanol (absolute grade), and 0.5
$\mathrm{mL}$ acetonitrile containing $2.0 \mathrm{mg} p$-NPP. The Cal-B solution was prepared by dissolving 50 $\mathrm{mg}$ Cal-B in $1 \mathrm{mg} / \mathrm{mL}$ buffer phosphate solution (PBS) at $\mathrm{pH}$ 7.0. An amount of $900 \mathrm{~mL}$ substrate solution was added into each of 300 $\mathrm{mL}$ Cal-B solution and immobilized Cal-B membranes. They were gently stirred and then incubated for 15 minutes in a shaker at $30{ }^{\circ} \mathrm{C}$ and $100 \mathrm{rpm}$. The immobilized Cal-B membrane and its solution were separated by decantation technique and Cal-B solution was used as a control.

The activities of Cal-B immobilized were investigated by determining the absorbance of $p$ nitrophenol ( $p$-NP) as the hydrolyzed product of $p$-NPP. The concentration of $p$-NP as the product was determined by UV/vis spectrophotometry analysis using $l_{\max }$ of $420 \mathrm{~nm}$. In this study, Cal-B was immobilized onto PES membrane, therefore the unit activity of the immobilized Cal-B was defined as mmol $p$ $\mathrm{NP} / \mathrm{cm}^{2} / \mathrm{min}$. The activity of Cal-B and immobilized Cal-B membrane were calculated by a formula:

$$
\text { Lipase activity }=\frac{C_{p N P}}{15}
$$

where, $C_{p N P}$ is the concentration of released $p$ $\mathrm{NP}$, which is taken from the hydrolysis product's absorbance and 15 is the reaction time which had been used.

\subsubsection{FTIR-ATR measurement}

Attenuated Total Reflectance FTIR-ATR method was used to investigate the alteration of membrane structure caused by the immobilization process. The FTIR-ATR measurements of 'Cal-B immobilized' membrane and PES blended membrane were performed at room temperature. The membrane samples were puton Zinc Selenide ( $\mathrm{ZnSe}$ ) glass in close contact. The ATR-FTIR spectrum was taken from 400 to $4000 \mathrm{~cm}^{-1}$.

\subsubsection{SEM measurement}

The surfaces of Cal-B immobilized in PESblended membranes were observed by SEM using an accelerating voltage of $10 \mathrm{kV}$ and $1000 \mathrm{x}$ magnification.

\section{Results and Discussion}

\subsection{Synthesis of PES}

The PES was synthesized according to polycondensation reaction. Polycondensation reaction was carried out through the reaction be- 
tween 4,4'-dichlorodiphenylsulfone (DCDPS) and hydroquinone that having two active groups, which are $-\mathrm{Cl}$ and $-\mathrm{OH}$ groups, respectively [19]. Water molecules as side product of this reaction was eliminated by adding toluene in azeotrope condition and the reaction was performed using reactor equipped with DeanStark trap apparatus to remove water from the system. Keitoku et al. [18] and Handayani et al. [17] have synthesized PES by conventional methods, which needed three hours reflux due to slow heat transfer process. MAOS methods using oven microwave oven reactor and a DeanStark trap apparatus attachment is the renewable of this research. It has an efficient direct thermal heating which needed only 66 minutes using a power of $300 \mathrm{~W}$. This method gave the advantages from the point of view of using quite low frequency to generate dipole movement of reaction mixtures directly [17-18,20].

Dielectric heating process of microwaveassisted reaction was derived from NMP as solvent used in this reaction which has a dielectric constant (e) of 34.22 [20]. Dielectric heating process was also supported by the polarizability structure of hydroquinone and DCDPS having a total dielectric constant (e) of 27.72, which promoted the activation of depolarization process of molecules rotation directly and increased the kinetic energy to create molecular collision of the reactants [17-20]. Hence, MAOS method is faster than conventional method in performing reactions including the polymerization reaction [20].

\subsection{Characterization of PES polymer by FTIR and ${ }^{1} \mathrm{H}-\mathrm{NMR}$}

The FTIR analysis of the synthesized product (PES) was performed to identify the new functional group peaks indicating the formation of new bonds in the polymer. The FTIR spectrum of the synthesized PES was presented in Figure 1. The FTIR spectrum of the synthesized PES showed the characteristic peaks of PES at $1234.44 \mathrm{~cm}^{-1}$ and $1103.28 \mathrm{~cm}^{-1}$ corresponded to the $\mathrm{C}-\mathrm{O}-\mathrm{C}$ bonds; while peaks at $1184.29 \mathrm{~cm}^{-1}$ and $1149.57 \mathrm{~cm}^{-1}$ represented the symmetric bond vibration of sulfonate $\left(-\mathrm{SO}_{2}-\right)$ groups and peaks at $1010.70 \mathrm{~cm}^{-1}$ showed the aromatic vibrations [23-24].

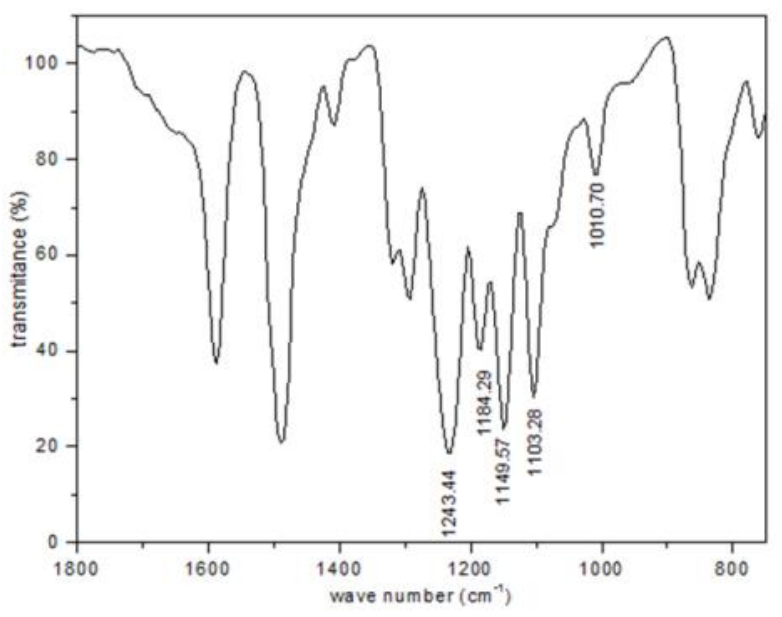

Figure 1. The FTIR spectrum of PES synthesized by MAOS method

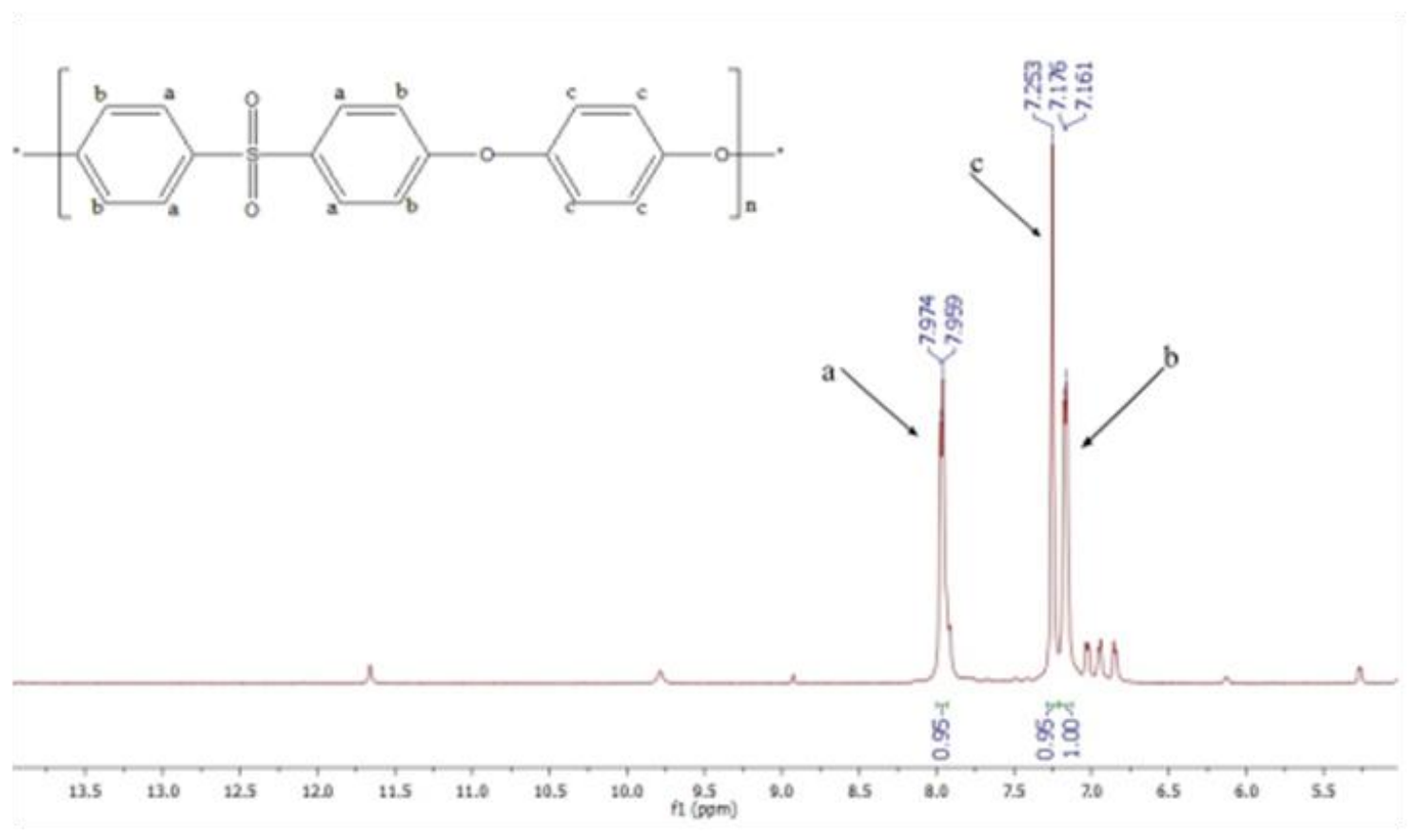

Figure 2. The ${ }^{1} \mathrm{H}-\mathrm{NMR}$ spectrum of the synthesized PES 
The elucidation structure of the synthesized PES was performed using ${ }^{1} \mathrm{H}-\mathrm{NMR}$ measurement and its spectrum was presented in Figure 2. The ${ }^{1} \mathrm{H}-\mathrm{NMR}$ spectrum of the synthesized PES (500 MHz, DMSO-d $)$ showed aromatic proton signals at chemical shift of $7.98 \mathrm{ppm}$ (ortho towards $-\mathrm{SO}_{2}$ - groups, meta towards -Obonds); 7.99 ppm (ortho towards $-\mathrm{SO}_{2-}$ ); 7.25 ppm (proton of aryl ether); 7.18 ppm (meta towards end groups of $4,4^{\prime}$ dichlorodiphenylsulfone residue); and $7.16 \mathrm{ppm}$ (ortho towards -O- bonds). Thus, based on the analyzed ${ }^{1} \mathrm{H}$-spectrum, it was confirmed that PES have been successfully synthesized using MAOS method [23,25].

\subsection{Immobilized lipase}

The characterization of 'Cal-B immobilized' PES-blended membrane was carried out by ATR-FTIR method to investigate the interaction between PES membranes and Cal-B. The ATR-FTIR spectrum of 'Cal-B immobilized' PES blended membrane and PES membrane were shown in Figure 3. After immobilization, a new peak associated to the stretching vibrations of $-\mathrm{N}-\mathrm{H}$ and $-\mathrm{OH}$ groups appeared at $3196.5 \mathrm{~cm}^{-1}$. The spectrum of the 'Cal-B immobilized' membrane also indicated the increase of peak's transmittance referred to the $-\mathrm{NH}$ deformation at $1654.31 \mathrm{~cm}^{-1}$, while the increase of transmittance at $1482.64 \mathrm{~cm}^{-1}$ corresponded to $-\mathrm{CH}_{2}$ deformation [23]. So, the presence of aforementioned characteristic peaks showed intermolecular interactions occurred between the Cal-B and the PES/polysulfone-blended membrane.

\subsection{SEM imaging}

Figure 4 showed the morphology of the original PES/polysulfone-blended membrane and the 'Cal-immobilized' one. The PES mem- brane showed some particulates with a diameter range of $0.425-0.876 \mathrm{~mm}$.

Figure 4(b) showed that white agglomerated granules of Cal-B were adsorbed on the membrane surface. The gravity force allowed the enzyme to fill the vacancies of membrane pores [27,28]. Chauhan et al., Gupta et al., and Wang et al. have done lipase immobilized onto several kinds of membranes, and they found that the membrane surfaces had some beads in clusters [24-26]. Regarding the differences of SEM images shown in Figure 4, it can be concluded that lipase was successfully immobilized into the membrane [30].

\subsection{Enzyme loading}

The determination of enzyme loading has been carried out by Lowry assay with BSA standard. The results of Lowry assay showed

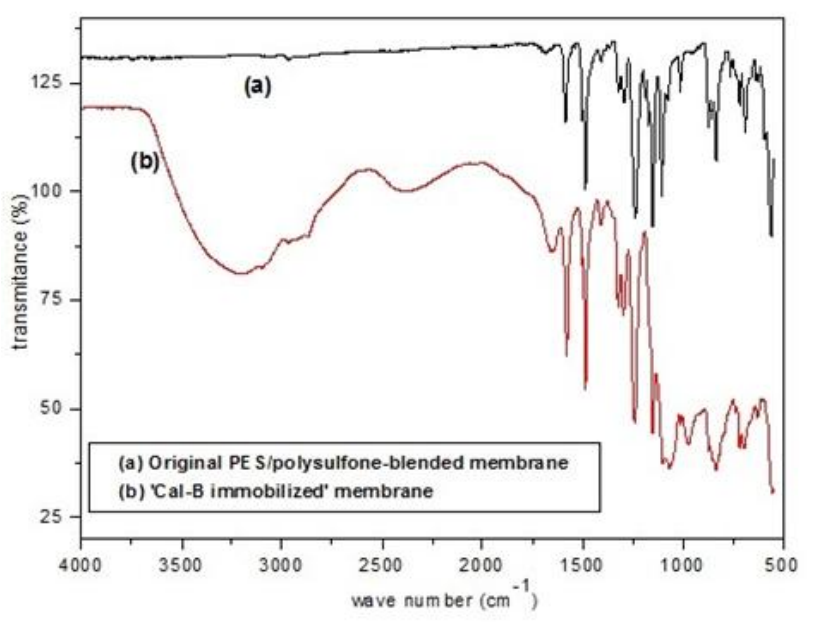

Figure 3. The FTIR-ATR spectra of and the original PES / polysulfone-blended membrane (before the immobilization of Cal-B): (a) PES / polysulfone-blended membrane, (b) 'Cal-B immobilized' membrane.
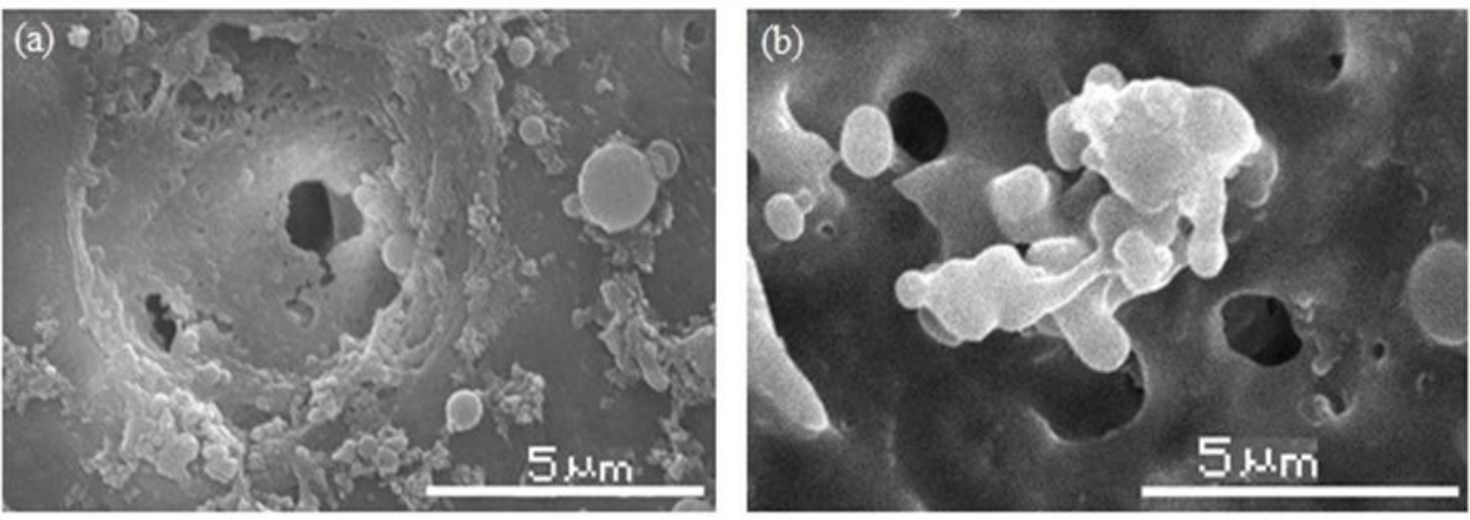

Figure 4. SEM images of the surfaces of: (a) original PES/polysulfone-blended membrane, and (b) 'CalB immobilized' PES/polysulfone-blended membrane 
that the 'Cal-B immobilized' blendedmembrane has the loading capacity of 91 $\mathrm{mg} / \mathrm{cm}^{2}$ in $17.34 \mathrm{~cm}^{2}$ of membrane surface area. The enzyme loading represented the quantity of Cal-B attached on the matrix (PES / polysulfone-blended membrane) by physisorption or covalent interaction [31]. The negatively charged groups of PES might interact with electropositive groups of amino acid residues from the active binding sites of Cal-B. The possible intermolecular interactions between the Cal-B and PES/polysulfone-blended membrane are considered weak to moderate interactions, such as hydrogen bonding, van der Waals, London dispersion, and electrostatic interactions. Jesionowski et al. [32] and Feng et al. [33] explained that the moderate intermolecular interaction between enzyme and matrix is the most important factor of the immobilization system because it would minimize the disturbance of the active site of enzyme. Therefore, the enzyme would still have the catalytic capability $[29,30]$. In this study, the physical intermolecular interactions between Cal-B lipase and the blended-membrane was proved to have a minimum disturbance on the activity of enzyme.

\subsection{Lipase activity}

The enzyme activities of ' $\mathrm{Cal}-\mathrm{B}$ immobilized' blended-membrane were investigated by determining the absorbance of $p$-Nitrophenol ( $p$-NP) based on the the release of $p$-NP hydrolyzed from $p$-NPP with the free enzyme as a control. The specific enzyme activity of the immobilized lipase membrane was found to be $80.43 \mathrm{mmol} p$-NP $\mathrm{min}^{-1} \mathrm{~cm}^{2}$, which was up to 2.5 times higher than the native enzyme (33.79 mmol $p$-NP $\min ^{-1} \mathrm{~cm}^{2}$ ). This result indicated that the synthesized PES showed good performance when used as matrix (blendedmembrane) in the immobilization of Cal-B, because the immobilized lipase was found to have a greater enzyme activity compared to its free form.

\section{Conclusions}

PES was synthesized by MAOS method and confirmed by the results of FTIR and 1H-NMR spectra analysis. The blended PES-polysulfone membrane was also prepared and confirmed structurally by ATR-FTIR spectra and its SEM image. The 'Cal-B immobilized' blendedmembrane was successfully prepared according to the analysis of FTIR-ATR spectra and its SEM image. The results of Lowry assay showed that the 'Cal-B immobilized' blendedmembrane had a loading capacity of $91 \mathrm{mg} / \mathrm{cm}^{2}$ in $17.34 \mathrm{~cm}^{2}$ of membrane surface area. The specific enzyme activity of the immobilized lipase membrane was found to be $80.43 \mathrm{mmol}$ $p$-NP $\min ^{-1} \mathrm{~cm}^{2}$, which was more than twice higher than the native enzyme $(33.79 \mathrm{mmol}$ $p$-NP $\min ^{-1} \mathrm{~cm}^{2}$ ). The results indicated that the synthesized PES showed good performance when used as matrix in the immobilization of Cal-B.

\section{Acknowledgement}

This research was funded by Decentralization Research from Ministry of Research, Technology and Higher Education of the Republic of Indonesia year 2015 - 2016, for which we are very thankful. Our gratitude goes also to the Geological Research and Development Center (PPGL) Bandung for SEM analysis. We also thank Prof. Dr. Yana Maolana Syah for the measurement of ${ }^{1} \mathrm{H}-\mathrm{NMR}$ spectrum in ITB (Institut Teknologi Bandung).

\section{References}

[1] Miletic, N., Abets, V., Ebert, K., Loos, K. (2016). Immobilization of Candida antarctica Lipase B on Polystyrene Nanoparticles Immobilization of Candida antarctica Lipase B on Polystyrene Nanoparticles. Macromolecular Rapid Communications, 31: 71-74.

[2] Sheldon, R.A. (2007). Cross-linked Enzyme Aggregates (CLEA s): Stable and Recyclable Biocatalysts. Proceedings of the Seventh International Conference on Protein Stabilization, 1583-1587, Exeter, UK.

[3] Sonntag, N.O.V. (1984). New Developments in the Fatty Acid Industry in America. Journal of the American Oil Chemists' Society, 61: 229-232.

[4] Stitt, E.H., Weatherley, L.R. (1994). Aqueous Two-phase Extraction Systems. in Bioengineeering Processes for Bioseparations, L.R. Weatherley, Ed. Elsevier, pp. 202-232.

[5] Rahimpour, A., Jahanshahi, M., Khalili, A., Mollahosseini, A., Zirepour, A., Rajaeian, B. (2012). Novel Functionalized Carbon Nanotubes for Improving the Surface Properties and Performance of Polyethersulfone (PES) Membrane. Desalination, 286: 99-107.

[6] Mu, L., Zhao, W. (2009). Applied Surface Science Hydrophilic Modification of Polyethersulfone Porous Membranes via a Thermalinduced Surface Crosslinking Approach. Applied Surface Science, 255: 7273-7278.

[7] Zhi, G., Yang, Y., Suiyi, Y., Jiancong, L., Dejun, B., Xia, Y., Hongliang, H., Mingxing, H. (2017). Comparing Polyethersulfone and Polyurethane-immobilized Cells of Coma- 
monas testosteroni QYY in Treatment of an Accidental Dye Wastewater. Chemical Research in Chinese Universities, 33(1): 36-43.

[8] Chen, G., Kuo, C., Chen, C., Yu, C., Shieh C., Liu, Y. (2012). Effect of Membranes with Various Hydrophobic/Hydrophilic Properties on Lipase Immobilized Activity and Stability. Journal of Bioscience and Bioengineering, 113(2): 166-172.

[9] Liu, Z,. Deng, X., Wang, M., Chen, J., Zhang, A., Gu, Z., Zhao, C. (2009). BSA-modified Polyethersulfone Membrane: Preparation, Characterization, and Biocompatibility. Journal of Biomaterials Science, Polymer Edition, 20: 377-397.

[10] Wang, L., Cai, Y., Jing, Y., Zhu, B.L., Zhu, $\mathrm{Xu}$, Y. (2014). Route to Hemocompatible Polyethersulfone Membranes via Surface Aminolysis and Heparinization. Journal of Colloid and Interface Science, 422: 38-44.

[11] Hir, Z.A.M., Moradihamedani, P., Abdullah, A.H., Mohamed, M.A. (2017). Immobilization of $\mathrm{TiO}_{2}$ into Polyethersulfone Matrix as Hybrid Film Photocatalyst for Effective Degradation of Methyl Orange Dye. Materials Science in Semiconductor Processing, 57: 157165.

[12] Idris, A., Bukhari, A. (2012). Immobilized Candida antarctica Lipase B: Hydration, Stripping off and Application in Ring Opening Polyester Synthesis. Biotechnology Advances, 30(3): 550-563.

[13] Wannerberger, K., Arnebrant, T. (1997). Comparison of the Adsorption and Activity of Lipases from Humicola lanuginosa and Candida antarctica on Solid Surfaces. Langmuir, 7463(18): 3488-3493.

[14] Mateo, C., Palomo, J.M., Lorente, F.G., Guisan, J.M., Lafuente, F.R. (2007). Immobilization of Enzymes on Heterofunctional Epoxy Supports. Nature Protocols, 2(5): 1022-1033.

[15] Lafuente, F.R., Armisen, P., Sabuquillo, P., Lorente, A.F., Guisan, J.M. (1998). Immobilization of Lipases by Selective Adsorption on Hydrophobic Supports. Chemistry and Pysics Lipids, 93: 185-197.

[16] Mehrasbi, M.R., Mohammadi, J., Peyda, M., Mohammadi, M. (2017). Covalent Immobilization of Candida antarctica Lipase on Coreshell Magnetic Nanoparticles for Production of Biodiesel from Waste Cooking Oil. Renewable Energy, 101: 593-602.

[17] Handayani, N., Buchari, M., Loos, K., Wahyuningrum, D. (2011). Properties of Synthesized Chlorosulfonated Polyethersulfone and Polyethersulfone Membranes as Solid Support for Lipases Immobilization. Proceedings of the second International Seminar on Chemistry, 21-25. Bandung, Indonesia.
[18] Keitoku, F., Kakimoto, M-A., Imai, Y. (1994). Synthesis and Properties of Aromatic Poly(ether sulfone)s and Poly(ether ketone)s Based on Methyl-substituted Biphenyl-4,4'Diols. Journal of Polymer Science Part A: Polymer Chemistry, 32: 317-322.

[19] Tsuchiya, K., Ishida, Y., Higashihara, T., Kameyama, A., Ueda, M. (2015). Synthesis of Poly(arylene ether sulfone): 18-Crown-6 Catalyzed Phase-transfer Polycondensation of Bisphenol A with 4,4'-Dichlorodiphenyl Sulfone. Polymer Journal, 47(5): 353-354.

[20] Kappe, C.O., Dallinger, D., Murphree, S.S. (2009). Practical Microwave Synthesis for Organic Chemist. Wiley-VCH Verlag GmbH.

[21] Kappe, C.O., Pieber, B., Dallinger, D. (2012). Microwave Effects in Organic Synthesis-myth or Reality. Angewandte Chemie International Edition, 51: 2-9.

[22] Hoz, A.H., Diaz-Ortiz, A., Moreno, A. (2005). Microwaves in Organic Synthesis. Thermal and Non-thermal Microwave Effects. Chemical Society Reviews, 34: 164-17.

[23] Silverstein, R., Webster,F. (1998). Spectrometric Identification of Organic Compounds. New York, John Wiley and Sons, Inc.

[24] Haider, M.S., Shao, G.N., Imran, S.M., Park, S.S., Tahir, M.S., Hussain, M., Bae, W., Kim, H.T. (2016). Aminated polyethersulfone-silver nanoparticles (AgNPs-APES) composite membranes with controlled silver ion release for antibacterial and water treatment applications. Materials Science and Engineering $C$, 62: $732-745$.

[25] Keitoku, F., Kakimoto, M-A., Imai, Y. (1994). Synthesis and Properties of Aromatic Poly(ether sulfone) sand Poly(ether ketone)s Based on Methyl substituted Biphenyl-4,4'Diols. Journal of Polymer Science Part A: Polymer Chemistry, 32: 317-322

[26] Clark, D.S., Baileyt, J.E. (1985). A Mathematical Model for Restricted Diffusion Effects on Macromolecule Impregnation in Porous Supports. Biotechnology and Bioengineering, 27: 208-213.

[27] Chauhan, N., Narang, J., Pundir, C.S. (2014). Covalent Immobilization of Lipase, Glycerol Kinase, Glycerol-3- phosphate Oxidase and Horseradish Peroxidase onto Plasticized Polyvinyl Chloride (PVC) Strip and its Application in Serum Triglyceride Determination. Indian Journal of Medical Research, 139: 603609.

[28] Gupta, S., Bhattacharya, A., Murthy, C.N. (2013). Tune to Immobilize Lipases on Polymer Membranes: Techniques, Factors and Prospects. Biocatalysis and Agricultural Biotechnology, 2: 171-190. 
[29] Wang, Y., Hu, Y., Xu, J., Luo, G.,Dai, Y. (2007). Immobilization of Lipase with a Special Microstructure in Composite Hydrophilic CA/Hydrophobic PTFE Membrane for the Chiral Separation of Racemic Ibuprofen. Journal of Membrane Science, 293: 133-141.

[30] Petkar, M., Lali, A., Caimi, P., Daminati, M.. (2006). Immobilization of Lipases for Nonaqueous Synthesis. Journal of Molecular Catalysis B: Enzymatic, 39: 83-90.

[31] Zisis, T., Freddolino, P.L., Turunen, P., Teeseling, M.C.F., Rowan, A.E., Blank, K.G. (2015). Interfacial Activation of Candida antarctica Lipase B: Combined Evidence from Experiment and Simulation. Biochemistry, 54: 5969-5979.
[32] Jesionowski, T., Zdarta, J., Krajewska, B. (2014). Enzyme Immobilization by Adsorption: A Review. Adsorption, 20(5-6): 801-821.

[33] Feng, X., Patterson, D.A., Balaban, M., Emanuelsson, E.A.C. (2013). Enabling the Utilization of Wool as an Enzyme Support: Enhancing the Activity and Stability of Lipase Immobilized onto Woolen Cloth. Colloids and Surfaces B: Biointerfaces, 102: 526-533.

Selected and Revised Papers from The $2^{\text {nd }}$ International Seminar on Chemistry (ISoC 2016) (Surabaya, 26-27 July 2016) (http://chem.its.ac.id/isoc-2016/) after Peer-reviewed by Scientific Committee of ISoC 2016 and Peer-Reviewers of BCREC journal 